\title{
Rat liver dihydroxyacetone-phosphate acyltransferase: enzyme characteristics and localization studies
}

\author{
D. Hardeman and H. van den Bosch \\ Laboratory of Biochemistry, University of Utrecht, Utrecht (The Netherlands)
}

(Received 6 July 1988)

\begin{abstract}
Key words: Peroxisome; Dihydroxyacetonephosphate acyltransferase; Alkyldihydroxyacetonephosphate synthase; Transversal membrane localization; Proteolysis; Glycerone-phosphate acyltransferase; (Rat liver)
\end{abstract}

Peroxisomes were isolated from rat liver by pelleting a light mitochondrial (L) fraction over a $30 \%$ (w/v) Metrizamide layer. Peroxisomes were recovered as a loose pellet from the bottom of the tube and the purity of the peroxisomal fraction was calculated to be about $90 \%$. The characteristics of dihydroxyacetone-phosphate acyltransferase (DHAP-AT) in the light mitochondrial fraction and the purified peroxisomal fraction were compared. The behaviour of the enzyme in the two fractions was very similar, except for the effect of sodium fluoride, which stimulated the activity in the $L$ fraction 5-10-fold and in the peroxisomal fraction only 1.6-fold. This difference could be explained by the action of fluoride-sensitive acid phosphatases present in the $L$ fraction that dephosphorylate palmitoyl-coenzyme $A$, a substrate for DHAP-AT. The localizations of DHAP-AT and alkyldihydroxyacetone-phosphate synthase in the rat liver peroxisomal membrane were studied. It is shown that in intact peroxisomes, DHAP-AT and alkyl-DHAP synthase are resistant to proteolytic inactivation by trypsin, as is fatty acid $\beta$-oxidation activity, which served as a marker for the intactness of the peroxisomal membrane. Catalase was found not to be a suitable marker to assess peroxisome intactness in view of its relative insensitivity to trypsin. In 1-lauroyllysophosphatidylcholine-permeabilized peroxisomes, DHAP-AT, alkyl-DHAP synthase and $\beta$-oxidation activities were rapidly inactivated by trypsin. It is concluded that in rat liver peroxisomes, at least the active sites of the integral membrane proteins DHAP-AT and alkyl-DHAP synthase are localized exclusively at the inner surface of the peroxisomal membrane.

\section{Introduction}

Dihydroxyacetone-phosphate acyltransferase (DHAP-AT), the enzyme that acylates DHAP, is a

\footnotetext{
Abbreviations: BSA, bovine serum albumin; DHAP, dihydroxyacetone phosphate; DHAP-AT, dihydroxyacetone-phosphate acyltransferase (EC 2.3.1.42); Mops, 4-morpholinepropanesulphonic acid.
}

Correspondence; H. van den Bosch, Laboratory of Biochemistry, State University of Utrecht, Padualaan 8, $3584 \mathrm{CH}$ Utrecht, The Netherlands. key enzyme in the biosynthesis of ether phospholipids [1]. Initially, there was much controversy about the localization of the enzyme. In the last few years, however, it has become clear that the enzyme is localized almost exclusively in peroxisomes [1,2], although evidence for a separate enzyme in the microsomal fraction has also been reported [3]. A predominant peroxisomal localization is confirmed also by the finding that the enzyme is strongly deficient in tissues and cells [4-7] from Zellweger patients, which do not contain morphologically detectable peroxisomes [8,9]. On a Metrizamide density gradient, peroxisomes 
can be purified to a high degree [10-12]. This has facilitated further studies of the functions and characteristics of peroxisomal processes.

DHAP-AT has been studied extensively in either impure light microchondrial or microsomal fractions obtained upon differential centrifugation of tissue homogenates [2,13-15] or in gradientpurified peroxisomes [16-18], and much information about the characteristics of the enzyme is already available [19].

In this article, some properties of rat liver DHAP-AT in the light mitochondrial fraction and in a highly purified peroxisomal fraction are compared. The results from these studies are used to investigate the localization of the DHAP-AT and the alkyldihydroxyacetone-phosphate synthase (EC 2.5.1.26) in the peroxisomal membrane by proteolysis. It is shown that in rat liver peroxisomes, the active sites of DHAP-AT and alkyl-DHAP synthase are localized exclusively at the inside of the peroxisomal membrane.

\section{Materials and Methods}

\section{Materials}

L-[U- $\left.{ }^{14} \mathrm{C}\right]$ Glycerol 3-phosphate, ammonium salt $(171 \mathrm{mCi} / \mathrm{mmol})$ and $\left[1-{ }^{14} \mathrm{C}\right]$ hexadecanol (55 $\mathrm{mCi} / \mathrm{mmol}$ ) were obtained from Amersham, Buckinghamshire, U.K. Metrizamide (2-(3-acetamido-5- $N$-methylacetamido-2,4,6-triiodobenzamido)-2-deoxy-D-glucose), analytical grade, was from Nyegaard and Co. AS, Oslo, Norway. Bovine serum albumin (BSA), essentially fatty acid-free, was from Sigma, St. Louis, U.S.A. All enzymes were purchased from Boehringer, Mannheim, F.R.G. All other chemicals were from Merck, Darmstadt, F.R.G. and were of standard laboratory grade.

\section{Methods}

Isolation of peroxisomes. Livers from adult male Wistar rats were homogenized in a Potter-Elvehjem homogenizer in $0.25 \mathrm{M}$ sucrose $/ 2 \mathrm{mM}$ EDTA $/ 10 \mathrm{mM}$ Tris- $\mathrm{HCl}(\mathrm{pH} \mathrm{7.4)}$ to yield a $10 \%$ homogenate. After centrifugation at $600 \times g$ and $3600 \times \mathrm{g}$ for $10 \mathrm{~min}$ each, the $\mathrm{L}$ fraction was obtained by centrifugation at $25000 \times g$ for 10 $\mathrm{min}$. The pellet was washed once and resuspended in a small volume of sucrose buffer. Peroxisomes were isolated essentially according to the method described by Ghosh and Hajra [20], except that Metrizamide was used instead of Nycodenz. $2 \mathrm{ml}$ of resuspended $\mathrm{L}$ fraction (about $15 \mathrm{mg}$ protein) were layered on top of $15 \mathrm{ml}$ of $30 \%(\mathrm{w} / \mathrm{v})$ Metrizamide $(\rho=1.17 \mathrm{~g} / \mathrm{ml})$ containing $2 \mathrm{mM}$ EDTA and $10 \mathrm{mM}$ Tris- $\mathrm{HCl}(\mathrm{pH} 7.4)$. Centrifugation was carried out at $73000 \times g$ for $60 \mathrm{~min}$. Microsomes, mitochondria and lysosomes were found on top of the Metrizamide layer, whereas peroxisomes were recovered as a loose pellet on the bottom of the tube. To remove Metrizamide, the peroxisomal fraction was either dialyzed overnight against sucrose buffer, or was diluted 10 -fold with sucrose buffer, whereafter peroxisomes were pelleted by centrifugation at $25000 \times g$ for 10 min. The peroxisomal pellet was resuspended in a small volume of sucrose buffer. The whole procedure was carried out at $4^{\circ} \mathrm{C}$.

Enzyme assays. DHAP-AT was determined according to Davis and Hajra [21] as modified by Schutgens et al. [22]. The initial assay conditions were $75 \mathrm{mM}$ sodium acetate ( $\mathrm{pH} 5.5), 8 \mathrm{mM} \mathrm{NaF}$, $8 \mathrm{mM} \mathrm{MgCl}_{2}, 0.15 \mathrm{mM}$ palmitoyl-CoA added in a mixture with $0.4 \mathrm{mg}$ delipidated bovine serum albumin, $0.12 \mathrm{mM} \quad\left[\mathrm{U}-{ }^{14} \mathrm{C}\right] \mathrm{DHAP} \quad(20000$ $\mathrm{dpm} / \mathrm{nmol}$ ) and protein in a total volume of 100 $\mu \mathrm{l}$. Incubation was carried out for $30 \mathrm{~min}$ at $37^{\circ} \mathrm{C}$ unless otherwise specified and the reaction was terminated as described [22].

Alkyl-DHAP synthase was determined as described before [38,39]. The assay contained 100 $\mathrm{mM}$ Tris- $\mathrm{HCl}(\mathrm{pH} 8.5), 50 \mathrm{mM} \mathrm{NaF}, 0.05 \%(\mathrm{v} / \mathrm{v})$ Triton X-100, $0.24 \mathrm{mM}$ palmitoyl-DHAP, 0.11 $\mathrm{mM}\left[1-{ }^{14} \mathrm{C}\right]$ hexadecanol $(7000 \mathrm{dpm} / \mathrm{nmol})$ and peroxisomal protein in a total volume of $100 \mu \mathrm{l}$. Incubation was carried out for $40 \mathrm{~min}$ at $37^{\circ} \mathrm{C}$ and the reaction was terminated as described $[38,39]$. Established methods have been used to measure the marker enzymes catalase [23], esterase [24], succinate-cytochrome-c reductase $[25]$ and acid phosphatase [26]. Fatty acid $\beta$-oxidation activity was measured according to Lazarow [27]. Phosphate was measured according to Chen et al. [28] and protein according to Bradford [29], with BSA as a standard.

\section{Results}

Table I shows the results of a typical example of the purification of peroxisomes. As can be seen, 


\section{TABLE I}

ENZYME ACTIVITIES IN HOMOGENATE AND ISOLATED FRACTIONS

Specific activity is expressed in $\mu \mathrm{mol} \cdot \mathrm{min}^{-1} \cdot \mathrm{mg}^{-1}$ (catalase and esterase) or $\mathrm{nmol} \cdot \mathrm{min}^{-1} \cdot \mathrm{mg}^{-1}$ (DHAP-AT, succinate-cytochrome- $c$ reductase and acid phosphatase). Relative specific activity is expressed as the ratio of specific activity in the isolated fraction and that in the homogenate.

\begin{tabular}{|c|c|c|c|c|c|}
\hline \multirow[t]{2}{*}{ Enzyme } & \multicolumn{3}{|c|}{ Specific activity } & \multicolumn{2}{|c|}{$\begin{array}{l}\text { Relatively specific } \\
\text { activity }\end{array}$} \\
\hline & $\begin{array}{l}\text { homog- } \\
\text { enate }\end{array}$ & $\begin{array}{l}\text { L frac- } \\
\text { tion }\end{array}$ & $\begin{array}{l}\text { peroxi- } \\
\text { somes }\end{array}$ & $\begin{array}{l}\text { L frac- } \\
\text { tion }\end{array}$ & $\begin{array}{l}\text { peroxi- } \\
\text { somes }\end{array}$ \\
\hline Catalase & 0.56 & 3.02 & 12.37 & 5.4 & 22.1 \\
\hline DHAP-AT & 0.12 & 0.75 & 5.06 & 6.3 & 42.2 \\
\hline Esterase & 3.07 & 4.93 & 0.70 & 1.6 & 0.2 \\
\hline \multicolumn{6}{|l|}{ Succ. cyt.-c } \\
\hline reductase & 22.4 & 11.3 & 7.4 & 0.5 & 0.3 \\
\hline \multicolumn{6}{|l|}{ Acid phos- } \\
\hline phatase & 28.6 & 165.0 & 16.0 & 5.7 & 0.6 \\
\hline
\end{tabular}

peroxisomes are enriched 6-fold in the $\mathrm{L}$ fraction and 42-fold in the peroxisomal pellet compared to the homogenate. It is a well-known fact that catalase leaks out of the peroxisomes during the isolation procedure [30-32], and hence the DHAP-AT, which is membrane-bound, gives a more reliable estimation of the purification factor. Of the catalase activity in the $\mathrm{L}$ fraction, $36 \%$ was recovered in the purified peroxisomes, whereas this value was $60 \%$ for DHAP-AT. Contamination of the peroxisomal fraction with microsomes, mitochondria and lysosomes is very low, amounting to 4.5 , 6.6 and $1.1 \%$, respectively.

In Figs 1 and 2, some characteristics of the enzyme in the $L$ fraction and the peroxisomal fraction are compared. The time curves (Fig. 1A) show that the enzyme is very stable in the peroxisomal fraction, with a linear increase in product formation up to $2 \mathrm{~h}$. Product formation in the crude $L$ fraction reaches a plateau after $1 \mathrm{~h}$. The pH curves (Fig. 1B) show no marked differences between the two fractions. The enzyme has a broad $\mathrm{pH}$ optimum, from $\mathrm{pH}$ 6.5-8.0 and is still active at rather high $\mathrm{pH}$ values. Although the results show that the enzymatic activity is not optimal at $\mathrm{pH} 5.5$, this low $\mathrm{pH}$ was used in the comparative studies to avoid a contribution from the microsomal enzyme glycerol-3-phosphate acyltransferase to acyl-DHAP formation in the impure $\mathbf{L}$ fraction. The substrate concentration curves (Fig. 1C) are also very similar, and show maximal activity around $0.12 \mathrm{mM} \mathrm{DHAP.} \mathrm{Calcu-}$ lation of the kinetic constants from the results of this particular experiment yielded a $K_{\mathrm{m}}$ value of $0.06 \mathrm{mM}$ and a $V_{\max }$ of $0.8 \mathrm{nmol} / \mathrm{min}$ per $\mathrm{mg}$ for the $\mathrm{L}$ fraction. For purified peroxisomes, these values were $0.08 \mathrm{mM}$ and $9.4 \mathrm{nmol} / \mathrm{min}$ per $\mathrm{mg}$, respectively. The palmitoyl-CoA curves are also similar and show an optimal activity around 0.09 $\mathrm{mM}$ palmitoyl-CoA $/ 0.3 \mathrm{mg}$ BSA.

In Fig. 2, the effect of $\mathrm{MgCl}_{2}$ and $\mathrm{NaF}$ on the DHAP-AT activity is shown. At $2 \mathrm{mM}, \mathrm{MgCl}_{2}$ stimulates the enzymatic activity in the $\mathrm{L}$ fraction about $23 \%$ and that in purified peroxisomes only 7\% (Fig. 2A). At $8 \mathrm{mM}$, the stimulatory effect is completely lost. The effect of $\mathrm{NaF}$ on the enzymatic activity shows a marked difference between the $\mathrm{L}$ fraction and the peroxisomal fraction (Fig. 2B). At the optimal concentration of $4 \mathrm{mM}$ $\mathrm{NaF}$, the enzyme in the $\mathrm{L}$ fraction is stimulated 5-10-fold, whereas that in the purified peroxisomes is only stimulated 1.6 -fold.

In view of these differences, the effect of $\mathrm{NaF}$ was studied in more detail. Previously, the enhanced product formation in the presence of fluoride has been explained [2] by the well-known fact that fluoride inhibits phosphatases [33], which can dephosphorylate the substrate DHAP and/or the product of the DHAP-AT. However, in our experiments, the product of the reaction, acyl-DHAP was measured after trichloroacetic acid precipitation on filterpaper, and this method does not discriminate between acyl-DHAP and the dephosphorylated product acyldihydroxyacetone. Thus, the effects of NaF detected in Fig. 2 cannot be explained by dephosphorylation of product. The other possibility was that the substrates became dephosphorylated. Table 2, Expt. A shows that during the standard DHAP-AT assay, about 20 $\mathrm{nmol}$ phosphate is released and indeed, this release is severely inhibited by fluoride. Although there is a difference in free phosphate between the samples incubated in the presence and absence of $\mathrm{NaF}$, this appeared independent of whether or not DHAP was present, indicating that the released phosphate did not originate from DHAP. The other possibility was that the second substrate, 

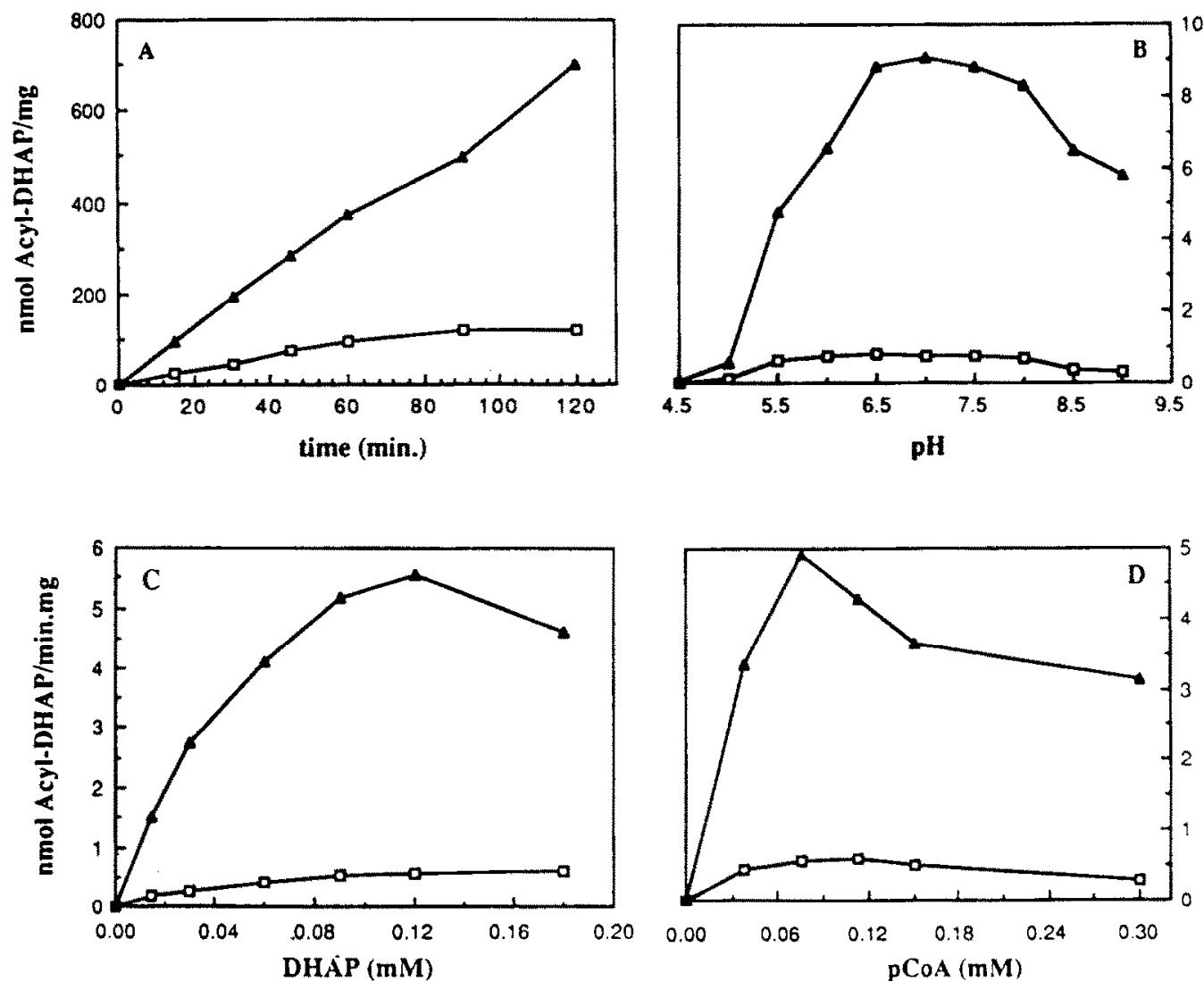

葛

Fig. 1. Properties of DHAP-AT in L fraction and purified peroxisomes from rat liver. L fraction protein (48 $\mu \mathrm{g}$, $\square$ ) and peroxisomal protein $(25 \mu \mathrm{g}, 4)$ were incubated in the presence of $75 \mathrm{mM}$ sodium acetate (pH 5.5$), 0.12 \mathrm{mM}$ DHAP, $0.15 \mathrm{mM}$ palmitoyl-CoA/0.4 $\mathrm{mg} \mathrm{BSA}, 8 \mathrm{mM} \mathrm{MgCl}$ and $8 \mathrm{mM} \mathrm{NaF}$ at $37^{\circ} \mathrm{C}$ for the indicated periods of time. (B) Assay contained either $100 \mu \mathrm{g} \mathrm{L}$ fraction protein $(\square)$ or $3.8 \mu \mathrm{g}$ peroxisomal protein $(\Delta)$. Incubation conditions were the same as in (A), except that $1.5 \mathrm{mM}$ glycerol 3-phosphate was present and incubation was carried out for $30 \mathrm{~min}$. Buffers used were: $75 \mathrm{mM}$ sodium acetate for pH $4.5-6.0,75$ $\mathrm{mM}$ Mops for $\mathrm{pH} 6.0-7.0$ and $75 \mathrm{mM}$ Tris-HCl for $\mathrm{pH} 7.0-9.0$. (C) Assays contained either $40.0 \mu \mathrm{g} \mathrm{L}$ fraction protein (D) or $11.4 \mu \mathrm{g}$ peroxisomal protein (A). Incubation conditions were the same as in (A) except that the DHAP concentration was varied as indicated. The incubation time was $30 \mathrm{~min}$. (D) Assays contained either $47.7 \mu \mathrm{g} \mathrm{L}$ fraction protein (D) or $11.4 \mu \mathrm{g}$ peroxisomal protein (A). Incubation was carried out for $30 \mathrm{~min}$ at $37^{\circ} \mathrm{C}$. Incubation conditions were the same as in (A), except that palmitoyl-CoA/BSA concentrations were varied as indicated, while keeping the palmitoyl-CoA/BSA ratio constant at $15 \mathrm{nmol} / 0.4 \mathrm{mg}$.
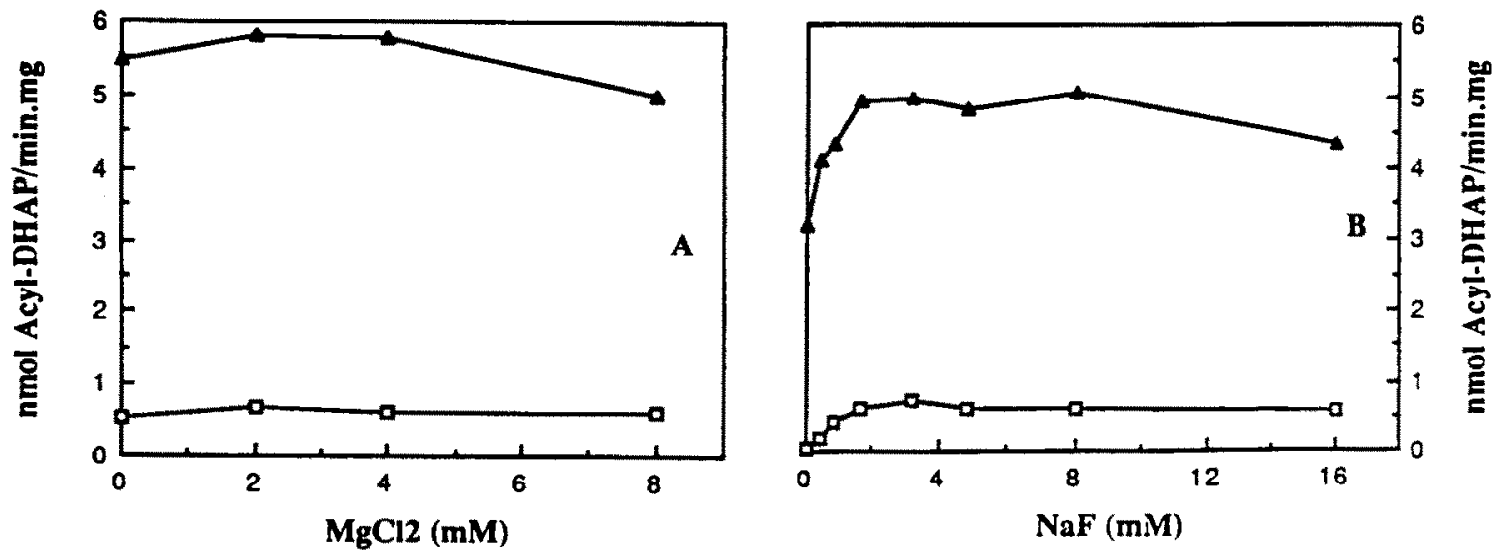

Fig. 2. Influence of $\mathrm{MgCl}_{2}$ and NaF on DHAP-AT in $\mathrm{L}$ fraction and purified peroxisomes from rat liver. (A) $\mathrm{L}$ fraction protein (56.4 $\mu \mathrm{g}, \mathrm{O})$ and $11.4 \mu \mathrm{g}$ peroxisomal protein (A) was incubated in the presence of $75 \mathrm{mM}$ sodium acetate (pH 5.5 ), $0.12 \mathrm{mM} \mathrm{DHAP,0.15}$ $\mathrm{mM}$ palmitoyl-CoA $/ 0.4 \mathrm{mg}$ BSA and $8 \mathrm{mM} \mathrm{NaF}$ at $37^{\circ} \mathrm{C}$ for $30 \mathrm{~min}$. The $\mathrm{MgCl}_{2}$ concentration was varied as indicated. (B) Incubation conditions were the same as in $(\Lambda)$ except that $8 \mathrm{mM} \mathrm{MgCl}$ was present and the $\mathrm{NaF}$ concentration was varied as indicated. 
TABLE II

RELEASE OF PHOSPHATE DURING A DHAP-AT ASSAY

(A) A standard DHAP-AT assay was carried out in the presence of $75 \mathrm{mM}$ sodium acetate ( $\mathrm{pH} 5.5$ ), $0.12 \mathrm{mM}$ palmitoylCoA $/ 0.3 \mathrm{mg}$ BSA and $80.0 \mu \mathrm{g} \mathrm{L}$ fraction protein in the presence or absence of $0.12 \mathrm{mM}$ DHAP (12 nmol) and in the presence or absence of $4 \mathrm{mM} \mathrm{NaF}$. After $30 \mathrm{~min}$ at $37^{\circ} \mathrm{C}, 200$ $\mu 1$ of $10 \%$ trichloroacetic acid was added and the protein was pellet for $10 \mathrm{~min}$ in an Eppendorf centrifuge. Free phosphate was determined in the supernatant according to Chen et al. [28]. (B) Incubation was carried out in the presence of $75 \mathrm{mM}$ sodium acetate ( $\mathrm{pH} 5.5$ ) and $78.5 \mu \mathrm{g}$ of $\mathrm{L}$ fraction protein and in the presence or absence of $0.12 \mathrm{mM}$ palmitoyl-CoA (12 $\mathrm{nmol}$ ) and in the presence or absence of $4 \mathrm{mM} \mathrm{NaF}$. Free phosphate was determined as in (A). (C) Incubation was carried out in the presence of $75 \mathrm{mM}$ sodium acetate $(\mathrm{pH} 5.5$ ) and $18.7 \mu \mathrm{g}$ of peroxisomal protein and in the presence of 0.12 $\mathrm{mM}$ palmitoyl-CoA (12 nmol) and in the presence or absence of $4 \mathrm{mM} \mathrm{NaF}$. Free phosphate was determined as in (A). (D) Incubation was carried out in the presence of $75 \mathrm{mM}$ Tris- $\mathrm{HCl}$ (pH 7.4) and $18.7 \mu \mathrm{g}$ of peroxisomal protein and in the presence of $0.12 \mathrm{mM}$ palmitoyl-CoA $(12 \mathrm{nmol})$ and in the presence or absence of $4 \mathrm{mM} \mathrm{NaF}$. Free phosphate was determined as in (A).

\begin{tabular}{lcllll}
\hline Experiment & \multicolumn{2}{l}{ Substrates added } & $\begin{array}{l}\mathrm{NaF} \\
(\mathrm{mM})\end{array}$ & $\begin{array}{l}\mathrm{P}_{\mathrm{i}} \text { released } \\
(\mathrm{nmol})\end{array}$ \\
\cline { 2 - 4 } & $\begin{array}{c}\text { DHAP } \\
(\mathrm{nmol})\end{array}$ & $\begin{array}{l}\text { palmitoyl- } \\
\text { CoA (nmol) }\end{array}$ & & \\
\hline A & - & 12 & - & 20.0 \\
& 12 & 12 & - & 19.2 \\
& - & 12 & 4 & 5.0 \\
& 12 & 12 & 4 & 3.4 \\
B & - & - & - & 3.5 \\
& - & 12 & - & 15.1 \\
& - & - & 4 & 0.0 \\
& - & 12 & 4 & 2.3 \\
C & - & 12 & - & 3.1 \\
& - & 12 & 4 & 0.9 \\
D & - & 12 & - & 2.0 \\
& - & 12 & 4 & 0.8 \\
\hline
\end{tabular}

palmitoyl-CoA became dephosphorylated. This possibility was born out in Expt. B, where incubations were performed in the absence or presence of palmitoyl-CoA. Addition of palmitoyl-CoA in the absence of fluoride caused an almost stoichiometric release of phosphate, and this was inhibited by over $80 \%$ by $4 \mathrm{mM}$ fluoride. When the same experiment was carried out with purified peroxisomes (Expt. C), only a small amount of phosphate was liberated, and this release was also severely inhibited by NaF. Expt. D shows that at a higher $\mathrm{pH}$, less phosphate is released, indicating that mainly (lysosomal) acid phosphatases are involved. The dephosphorylation of palmitoyl-CoA in the absence of fluoride can explain the large effects of $\mathrm{NaF}$ on palmitoyl-DHAP formation in the $\mathrm{L}$ fraction, whereas in purified peroxisomes, this effect has almost completely disappeared, because the peroxisomal fraction has lost most of its acid phosphatase activity (Table I).

In view of the above results, the incubation conditions for purified peroxisomes were slightly modified. The palmitoyl-CoA concentration was lowered to $0.12 \mathrm{mM}(0.3 \mathrm{mg} \mathrm{BSA})$, and the assay was performed at $\mathrm{pH}$ 7.4. $\mathrm{MgCl}_{2}$ was omitted completely, whereas the $\mathrm{NaF}$ concentration was lowered to $4 \mathrm{mM}$. Using these modified conditions, the localization of the DHAP-AT in the peroxisomal membrane was investigated. In agreement with previous results [2,17,34] trypsin can be used to proteolytically inactivate DHAP-AT in disrupted peroxisomes (Fig. 3A). However, high amounts of trypsin are needed to achieve complete inactivation of DHAP-AT, and under these conditions, catalase is still completely resistent. This demonstrates that the use of catalase as a marker for the intactness of the peroxisomes can easily give misleading results in that full recovery of catalase activity does not necessarily mean that the organelle remains intact. Secondly, to compare the effect of trypsin on intact and permeabilized peroxisomes, a detergent was needed to disrupt the membrane barrier. Other investigators have used sodium cholate [2] or Triton X-100 [34] for this purpose. We found, however, that these detergents themselves inactivated DHAP-AT to a large extent. This phenomenon has been described by others as well [17,22]. Fig. 2B shows the effect on enzymatic activity when peroxisomes are incubated in the presence of different detergents at $37^{\circ} \mathrm{C}$ for different periods of time. From this, it is clear that 1-lauroyllysophosphatidylcholine is the detergent of choice in that it shows the least deteriorating effect on DHAP-AT activity.

In Fig. 4, it is shown that also in the presence of lysophosphatidylcholine, catalase is resistant to trypsin digestion, from which it was concluded that another marker for the intactness of the peroxisomal membrane had to be found. 

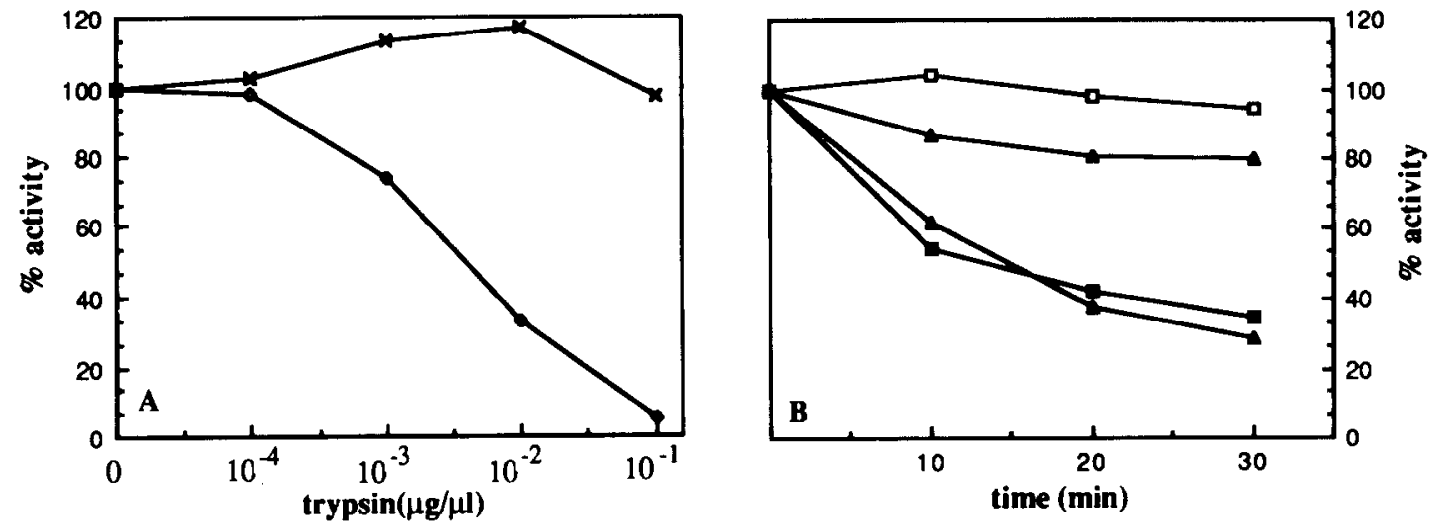

Fig. 3. Trypsin treatment of sonicated peroxisomes and influence of detergents on DHAP-AT activity. (A) peroxisomal protein was sonicated three times for $15 \mathrm{~s}$ on ice. Sonicated protein $(30 \mu \mathrm{g})$ was incubated in the presence of the indicated amounts of trypsin in a total volume of $200 \mu \mathrm{l}$ for $40 \mathrm{~min}$ at $37^{\circ} \mathrm{C}$. Trypsin inhibitor $(2 \mathrm{mg} / \mathrm{mg}$ trypsin) was added and DHAP-AT $(\diamond)$ and catalase $(\times)$ activity were determined as described. (B) Peroxisomal protein $(0.15 \mathrm{mg})$ was incubated in the presence of either $0.5 \%$ sodium cholate $(\Delta), 0.25 \%$ 3-[(3-cholamidopropyl)dimethylammonio]-1-propanesulfonate (CHAPS, $\Delta)$ or $0.025 \%$ Triton X-100 (ם) in a total volume of $200 \mu \mathrm{l}$. In the experiment with lysophosphatidylcholine ( $\square$ ), $0.5 \mathrm{mg}$ peroxisomal protein was incubated in the presence of $250 \mathrm{nmol}$ 1-lauroyllysophosphatidylcholine in $0.5 \mathrm{ml}$. Aliquots were removed after the indicated time periods, diluted 10-fold to avoid inhibition of the enzyme in the assay and aliquots of the diluted samples were used to determine DHAP-AT activity. 100\% activity represents $4.3 \mathrm{nmol}$ acyl-DHAP $\cdot \mathrm{min}^{-1} \cdot \mathrm{mg}^{-1}$.

Fig. 5 shows the effect of trypsin on DHAP-AT, alkyl-DHAP synthase and $\beta$-oxidation activity, which serves as a marker for the accessibility of trypsin to the peroxisomal matrix in intact and lysophosphatidylcholine-permeabilized per-

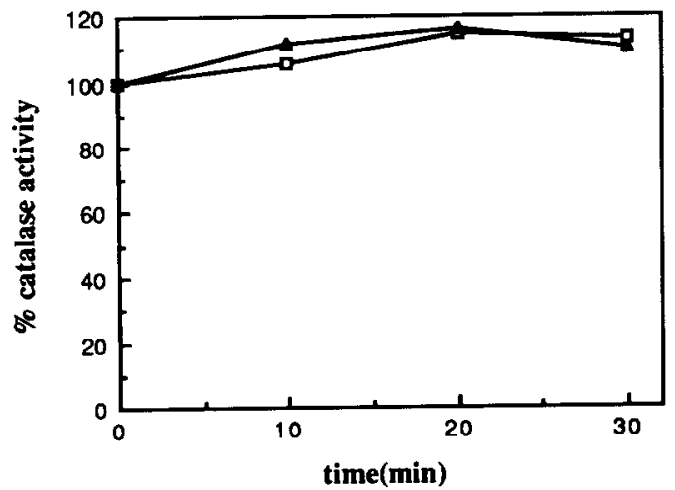

Fig. 4. Trypsin treatment of intact and lysophosphatidylcholine-permeabilized peroxisomes: effect on catalase activity. Peroxisomes $\left(0.1 \mathrm{mg}\right.$ protein) were incubated at $37^{\circ} \mathrm{C}$ in the presence of $50 \mathrm{nmol} 1$-lauroyllysophosphatidylcholine and in the presence or absence of $10 \mu \mathrm{g}$ trypsin in a total volume of $0.1 \mathrm{ml}$. After the indicated periods of time, aliquots of $20 \mu \mathrm{l}$ were removed and trypsin inhibitor $(10 \mu \mathrm{g})$ was added. Small samples were taken and sonicated whereafter catalase activity was determined. The $100 \%$ activity represents $12.2 \mu \mathrm{mol}$ $\min ^{-1} \cdot \mathrm{mg}^{-1}$. $\Delta$, with trypsin; $\square$, without trypsin. oxisomes. Fig. $5 \mathrm{C}$ shows that trypsin, when added in a $1: 50$ ratio to peroxisomal protein, does not inactivate DHAP-AT activity in intact peroxisomes. Under the same conditions, $\beta$-oxidation activity is decreased by maximally $10 \%$ (Fig. $5 \mathrm{~A}$ ). These results indicate that trypsin, under these conditions, does not have access to compartments inside the peroxisomal membrane. In the presence of lysophosphatidylcholine, which by itself has no deteriorating effect on $\beta$-oxidation activity (Fig. $5 \mathrm{~B})$, trypsin causes rapid inactivation of the $\beta$ oxidation of palmitoyl-CoA, indicating that lysophosphatidylcholine effectively permeabilizes the peroxisomal membrane (Fig. 5B). It is only under these conditions that rapid proteolytic inactivation of DHAP-AT activity is observed, even at the low ratio of trypsin to peroxisomal protein of 0.02 (Fig. 5D). These results are interpreted to indicate that at least the active site of DHAP-AT is located exclusively at the inside of the rat liver peroxisomal membrane.

Using almost the same conditions, except that a somewhat higher trypsin concentration had to be used, also the localization of alkyl-DHAP synthase was studied. In Fig. 5E, it is shown that in the absence of lysophosphatidylcholine, the enzyme is almost completely protected against pro- 

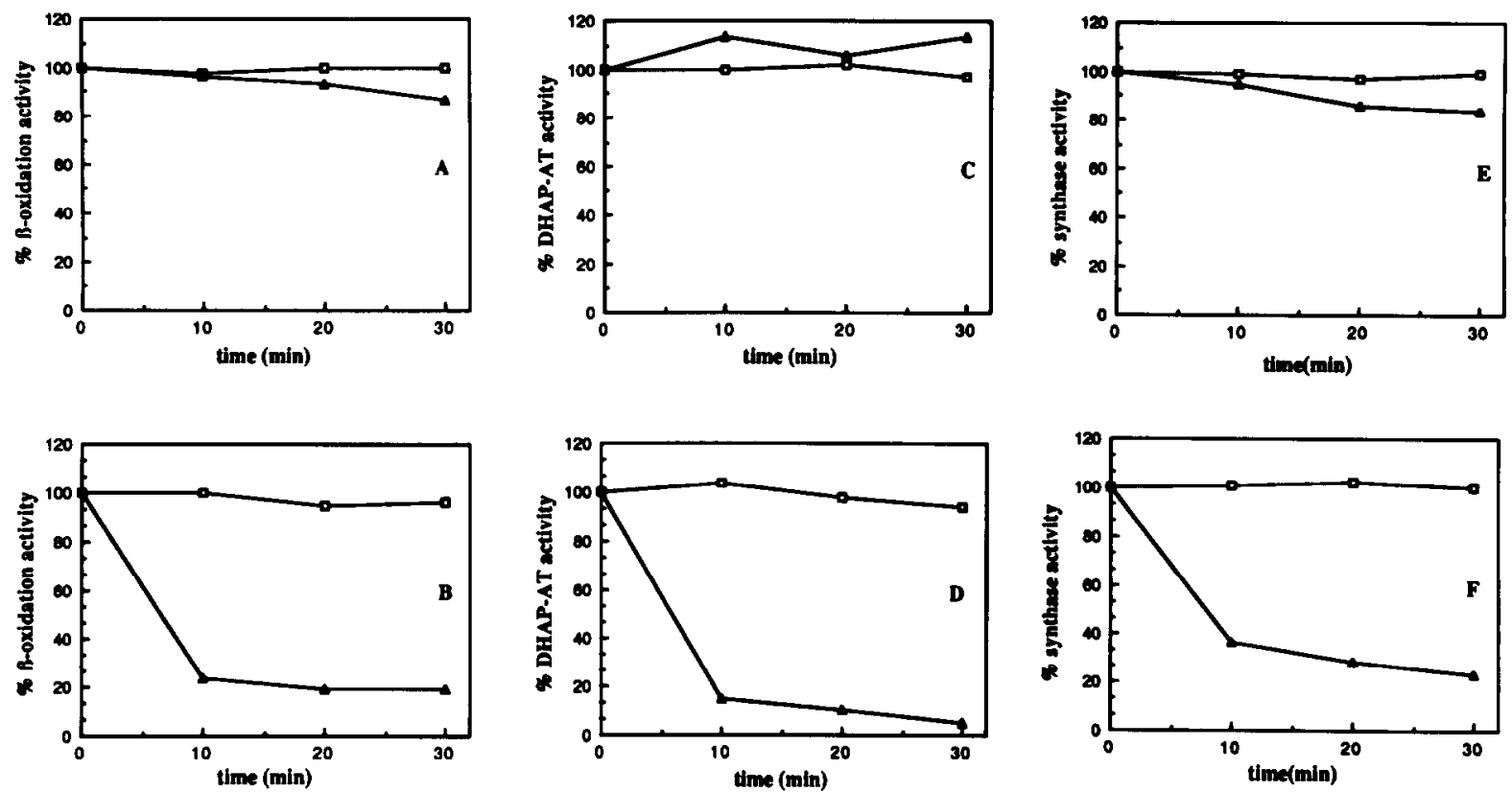

Fig. 5. Trypsin treatment of intact and lysophosphatidylcholine-permeabilized peroxisomes. Peroxisomes (0.5 mg protein) were incubated in the presence (A) or absence (D) of either $10 \mu \mathrm{g}$ (A-D) or $25 \mu \mathrm{g}$ (E,F) trypsin with (B,D,F) or without (A,C,E) 250 nmol 1-lauroyllysophosphatidylcholine. After the indicated time periods, aliquots of $100 \mu 1$ were removed, trypsin inhibitor and sucrose buffer were added to give a total volume of $200 \mu \mathrm{l}$, and aliquots were assayed for remaining activities of the indicated enzymes. $100 \%$ activities represent formation of $6.0 \mathrm{nmol}$ acyl-DHAP $\cdot \mathrm{min}^{-1} \cdot \mathrm{mg}^{-1}, 0.2 \mathrm{nmol}$ alkyl-DHAP $\cdot \mathrm{min}^{-1} \cdot \mathrm{mg}^{-1} \mathrm{and}^{-1} \mathrm{nmol} \mathrm{NADH}$. $\min ^{-1} \cdot \mathrm{mg}^{-1}$, respectively.

teolytic inactivation by trypsin, whereas in the presence of the detergent and trypsin, the enzymatic activity is lost (Fig. 5F). Thus, as has been shown for the DHAP-AT, also the alkyl-DHAP synthase is localized at the inner surface of the peroxisomal membrane.

\section{Discussion}

Peroxisomes have a much higher density than the other cellular organelles. This makes it unnecessary to use a density gradient to isolate peroxisomes. Ghosh and Hajra [20] have also shown that for the isolation, a normal fixed-angle rotor can be used. The method introduced by these investigators employs a layer of Nycodenz of a given density $(1.15 \mathrm{~g} / \mathrm{ml})$ containing $1 \mathrm{mM}$ tetrasodium EDTA ( $\mathrm{pH}$ 7.3). On top of this layer, a small volume of $\mathrm{L}$ fraction protein is introduced, whereafter centrifugation is carried out for $1 \mathrm{~h}$ at $130000 \times \mathrm{g}$. We have adapted this method slightly by using Metrizamide instead of Nycodenz and by buffering the density medium with $10 \mathrm{mM}$ Tris$\mathrm{HCl}$ ( $\mathrm{pH}$ 7.4). The centrifugation time and $g$ value are not very critical. After initial experiments, we routinely used $60 \mathrm{~min}$ at $73000 \times \mathrm{g}$. The results we obtained are comparable to those of Ghosh and Hajra [20]. These authors reported a 67-fold increase in the specific activity of DHAPAT as compared to a 42 -fold increase in our procedure. However, the contamination, as calculated by the method of Fujiki et al. [35], with microsomes and mitochondria amounted to 9 and $8 \%$, respectively, and were somewhat higher than the 4.5 and $6.6 \%$ found in our adapted method.

The characteristics of the DHAP-AT are comparable to what has been reported by other investigators. In the purified fraction, product formation is linear over a more extended period of time than in the $\mathrm{L}$ fraction. This may be explained by a much larger contamination of the $L$ - fraction with lysosomes (Table I) that contain enzymes capable of degrading substrates and/or product. The $\mathrm{pH}$ optimum is very broad, from pH 6.5 to 8.0 (Fig. 
1B), with a shoulder up to $\mathrm{pH} 9.0[2,17,19]$. Between $\mathrm{pH} 5.0$ and 6.5 , the enzymatic activity increases strongly with the $\mathrm{pH}$ and a small variation in $\mathrm{pH}$ results in large differences in product formation. For this reason and also in view of the fact that the purified peroxisomes are hardly contaminated by microsomes, a $\mathrm{pH}$ value of 7.4 was chosen for further experiments. From the DHAP curve, the $K_{\mathrm{m}}$ and $V_{\max }$ values were calculated. In agreement with DeClercq et al. [17], but in contrast to Jones and Hajra [2], we found no break in the reciprocal plot of the data for acyl-DHAP formation at $\mathrm{pH}$ 5.5. The $K_{\mathrm{m}}$ values of 0.06 and $0.08 \mathrm{mM}$ for $\mathrm{L}$ fraction and purified peroxisomes, respectively, are comparable to reported values $[2,17,19]$. This also holds for the $V_{\max }$ values in both fractions, which are 0.8 and $9.4 \mathrm{nmol} / \mathrm{min}$ per $\mathrm{mg}$, respectively. The optimal palmitoyl-CoA concentration is $0.09 \mathrm{mM}$. Bovine serum albumin is added together with palmitoyl-CoA to prevent formation of palmitoyl-CoA micelles, by which the enzymatic activity is reduced. Except for the influence of fluoride, no marked differences between the enzyme in the two different fractions were observed. $\mathrm{MgCl}_{2}$ is normally added in the assay, although the reason for this is not very clear. It has been stated to inhibit phosphatases [36], but it is clear from Fig. $2 \mathrm{~A}$ that it has, especially in purified peroxisomes, only a small stimulatory effect at low $\mathrm{MgCl}_{2}$ concentrations. At $8 \mathrm{mM} \mathrm{MgCl}$, the stimulatory effect is lost completely and for these reasons in further experiments $\mathrm{MgCl}_{2}$ was omitted from the incubation mixtures.

The effect of NaF has been explained by the fact that this (also) inhibits phosphatases [2]. We have shown that this is correct, but that it is not the substrate DHAP or the product acyl-DHAP, but palmitoyl-CoA which is prevented from dephosphorylation in the presence of fluoride.

The topographical distribution of the DHAPAT $[2,15,17,34]$ and the alkyl-DHAP synthase $[34,40]$ have also been studied before. Rock et al. concluded that both the DHAP-AT [15] and the alkyl-DHAP synthase [40] were present on the luminal side of the vesicles in a microsomal fraction, presumably containing peroxisomes, from Harderian gland. Bishop et al. [34] studied the localization of lipid biosynthetic enzymes in rat brain. They also concluded that the DHAP-AT and the alkyl-DHAP synthase were localized at the inside of the peroxisomal membrane. However, they used $0.04-0.05 \%$ Triton X-100 to permeabilize the peroxisomal membrane, and this amount of this detergent is sufficient to inhibit the DHAP-AT completely, even in the absence of trypsin (Fig. 3B) [22]. Attempts to localize the enzymes in rat liver peroxisomes were hampered by problems in kecping the membrane intact [34]. Jones and Hajra investigated the transmembrane distribution in guinea pig liver peroxisomes [2] and obtained evidence that the DHAP-AT was mainly localized at the inside of peroxisomes. However, these authors used very high amounts of trypsin (trypsin to protein ratio $=1.5$ ) and found with intact peroxisomes already $17 \%$ inactivation of DHAP-AT activity. In addition, they used $0.5 \%$ cholate to render the peroxisomal membranes permeable to trypsin. When we used the same concentration of cholate with rat liver peroxisomes. we found already $60 \%$ spontaneous inactivation after $30 \mathrm{~min}$ at $37^{\circ} \mathrm{C}$ (Fig. 3B). DeClercq et al. [17] also performed localization studies on DHAPAT in rat liver peroxisomes. They used high amounts of trypsin (trypsin to protein ratio varied from 0.07 to 0.7 ) and observed with intact peroxisomes already a $33 \%$ loss of DHAP-AT activity. At the same, time these authors also reported that under their conditions, catalase was not inactivated by trypsin. It has now become clear that resistance of catalase to trypsin cannot be used as an indication of peroxisome intactness (Figs. 3A. 4).

In this article, we describe a somewhat different approach for the determination of the transmembrane distribution of DHAP-AT and alkyl-DHAP synthase in peroxisomes in which lysophosphatidylcholine was used to permeabilize the membranes. This lysophosphatidylcholine detergent did not have any effect on the enzymatic activities of DHAP-AT, alkyl-DHAP synthase and $\beta$-oxidation enzymes when added in amounts sufficient to render the membrane permeable to trypsin. When trypsin was added in a trypsin to peroxisomal protein ratio of 0.02 , both the DHAP-AT activity and the $\beta$-oxidation capacity became susceptible to rapid inactivation, and at a ratio of 0.05 , also the alkyl-DHAP synthase was inactivated. In our 
approach, the $\beta$-oxidation enzymes, which are localized in the peroxisomal matrix [37], served as a marker for the intactness of the peroxisomes. Indeed, when intact peroxisomes were treated with the same amounts of trypsin, the DHAP-AT activity was preserved completely, whereas the $\beta$-oxidation and alkyl-DHAP synthase activities were about $90 \%$ preserved.

In summary, the method used to purify peroxisomes, which was introduced by Ghosh and Hajra [20] and was adapted slightly, gives good and reproducible results. Peroxisomes isolated in this way can be used to study the characteristics of peroxisomal enzymes. As is shown here, peroxisomes isolated in this way are stable and can be used for many purposes. We have shown that the organelles remain intact during subsequent incubations and we have used this property to establish that at least the active sites of rat liver DHAP-AT and alkyl-DHAP synthase are localized exclusively at the inside of the peroxisomal membrane.

\section{References}

1 Hajra, A.K. and Bishop, J.E. (1982) Ann. NY Acad. Sci. $386,170-182$.

2 Jones, C.L. and Hajra, A.K. (1980) J. Biol. Chem. 255 , 8289-8295.

3 Datta, N.S. and Hajra, A.K. (1984) FEBS Lett. 176, 264-268.

4 Schutgens, R.B.H., Romeijn, G.J., Wanders, R.J.A., Van den Bosch, H., Schrakamp, G. and Heijmans, H.S.A. (1984) Biochem. Biophys. Res. Commun. 120, 179-184.

5 Datta, N.S., Wilson, G.N. and Hajra, A.K. (1984) N. Engl. J. Med. 311, 1080-1083.

6 Van den Bosch, H., Schrakamp, G., Heijmans, H.S.A., Wanders, R.J.A., Tager, J.M. and Schutgens, R.B.H. (1986) in Enzymes of Lipid Metabolism II (Freysz, L., Dreyfus, H., Massarelli, R. and Gatt, S., eds.), pp. 209-217, Plenum Press, New York.

7 Wilson, G.N., Holmes, R.G., Custer, J., Lipkowitz, J.L., Stover, J., Datta, N.S. and Hajra, A.K. (1986) Am. J. Med. Gen. 24, 69-82.

8 Goldfischer, S., Moore, C.L., Johnson, A.B., Spiro, A.J., Valsamis, M.P., Wisniewski, H.K., Ritch, R.H., Norton, W.T., Rapin, I. and Gartner, L.M. (1973) Science 182, 62-64.

9 Arias, J.A., Moser, A.B. and Goldfischer, S.L. (1985) J. Cell Biol. 100, 1789-1792.

10 Wattiaux, R., Wattiaux-de Coninck, S., Roveaux-Dupal, M. and Dubois, F. (1978) J. Cell Biol. 78, 349-368.

11 Hajra, A.K. and Wu, D. (1985) Anal. Biochem. 148. 233-244.

12 Bronfman, M., Inestrosa, N.C. and Leighton, F. (1979) Biochem. Biophys. Res. Commun. 88, 1030-1036.
13 Hajra, A.K. and Burke, C. (1978) J. Neurochem. 31, 125-134.

14 Bates, E.J. and Saggerson, E.D. (1979) Biochem. J. 182 , $751-762$.

15 Rock, C.O., Fitzgerald, V. and Snyder, F. (1977) J. Biol. Chem. 252, 6363-6366.

16 Hajra, A.K., Burke, C.L. and Jones, C.L. (1979) J. Biol. Chem. 254, 10896-10900.

17 DeClercq, P.E., Haagsman, H.P., Van Veldhoven, P., Debeer, L.J., Van Golde, L.M.G. and Mannaerts, G.P. (1984) J. Biol. Chem. 259, 9064-9075.

18 Dobrowsky, R.T. and Ballas, L.M. (1987) J. Biol. Chem. $262,3136-3139$.

19 Jones, C.L. and Hajra, A.K. (1983) Arch. Biochem. Biophys. 226, 155-165.

20 Ghosh, M.K. and Hajra, A.K. (1986) Anal. Biochem. 159, 169-174.

21 Davis, P.A. and Hajra, A.K. (1979) J. Biol. Chem. 254, 4760-4763.

22 Schutgens, R.B.H., Romeijn, G.J., Ofman, R., Van den Bosch, H., Tager, J.M. and Wanders, R.J.A. (1986) Biochim. Biophys. Acta 879, 286-291.

23 Holmes, R.S. and Masters, C.J. (1970) FEBS Lett. 11, 45-48.

24 Beaufay, H., Amar-Costesec, A., Feytmans, E., ThinesSempoux, D., Wibo, M., Robbi, M. and Berthet, J. (1974) J. Cell Biol. 61, 188-200.

25 Schnaitman, G. and Greenawalt, J.W. (1968) J. Cell Biol. $38,158-169$.

26 Walter, K. and Schütt, C. (1974) in Methods of Enzymatic Analysis (Bergmeijer, H.U., ed.), pp. 856-860, Verlag Chemie, Weinheim.

27 Lazarow, P.B. (1981) Methods Enzymol. 72, 315-319.

28 Chen, P.S., Toribara, T.Y. and Warner, H. (1956) Anal. Chem. 28, 1756-1758.

29 Bradford, M.M. (1976) Anal. Biochem. 72, 248-254.

30 Leighton, F.B., Poole, B., Beaufay, H., Baudhuin, P., Cof fey, J.W. and De Duve, C. (1968) J. Cell Biol. 37, 482-513.

31 Lazarow, P. and De Duve, C. (1973) J. Cell Biol. 59, 507-524.

32 Alexon, S.E.H., Fujiki, Y., Shio, H. and Lazarow, P.B. (1985) J. Cell Biol. 101, 294-305.

33 Sedgwick, B. and Hübscher, G. (1967) Biochim. Biophys. Acta $144,397-408$

34 Bishop, J.E., Salem, M. and Hajra, A.K. (1982) Ann. NY Acad Sci. 386, 411-413.

35 Fujiki, Y., Fowler, S., Shio, H., Hubbard, A.L. and Lazarow, P.B. (1984) J. Cell Biol. 93, 97-102.

36 Hajra, A.K. (1968) J. Biol. Chem. 243, 3458-3465.

37 Yokota, S. and Fahimi, H.D. (1982) Ann. NY Acad. Sci. 386, 491-494.

38 Brown, A.J. and Snyder, F. (1983) J. Biol. Chem. 258, 4181-4189.

39 Schrakamp, G., Roosenboom, C.F.P., Schutgens, R.B.H., Wanders, R.J.A., Heymans, H.S.A., Tager, J.M. and Van den Bosch, H. (1985) J. Lipid Res. 26, 867-873.

40 Rock, C.O., Fitzgerald, V. and Snyder, F. (1977) Arch. Biochem. Biophys. 181, 172-177. 